\title{
Immigration and Employer Transitions for STEM Workers
}

\section{Citation}

Pekkala Kerr, Sari, and William R. Kerr. "Immigration and Employer Transitions for STEM Workers." American Economic Review: Papers and Proceedings (forthcoming).

\section{Permanent link}

http://nrs.harvard.edu/urn-3:HUL.InstRepos:10684309

\section{Terms of Use}

This article was downloaded from Harvard University's DASH repository, and is made available under the terms and conditions applicable to Open Access Policy Articles, as set forth at http:// nrs.harvard.edu/urn-3:HUL.InstRepos:dash.current.terms-of-use\#OAP

\section{Share Your Story}

The Harvard community has made this article openly available.

Please share how this access benefits you. Submit a story.

\section{Accessibility}




\title{
Immigration and Employer Transitions for STEM Workers
}

\author{
By Sari Pekkala Kerr and William R. Kerr*
}

* Pekkala Kerr: Wellesley College, 106 Central Street, Wellesley, MA 02481 (e-mail: skerr3@wellesley.edu). Kerr: Harvard University, NBER, and Bank of Finland, Rock Center 212, Harvard Business School, Boston, MA 02163 (wkerr@hbs.edu). We especially thank Daniel Goroff and the Sloan Foundation for financial support for this project; Giovanni Peri for an excellent AEA discussion; and George Borjas, Jim Davis, Julia Lane, Paul Oyer, and Sarah Turner for very helpful comments. This research was conducted while the authors were Special Sworn Status researchers of the US Census Bureau at the Boston Census Research Data Center (BRDC). Research results and conclusions expressed are the authors' and do not necessarily reflect the views of the Census Bureau or NSF. This paper has been screened to ensure that no confidential data are revealed.

Immigrants play a significant role in many aspects of the U.S. economy, but their impact in occupations related to science, technology, engineering, and mathematics (STEM) is especially pronounced. Immigrants account for about a quarter of all STEM workers with college degrees or higher in the 2000 Census, and about half of those with doctorates. Much of the recent growth in U.S. employment in STEM occupations is linked to immigrants.

Given the importance of innovation for economic growth, the economic consequences of immigrants in STEM occupations have been closely examined in recent research. Of particular importance has been the impact of STEM immigrants on the employment opportunities and wages of native workers, how immigrants impact the aggregate innovation rate of the U.S. economy, and similar research questions. Studies in this literature have often employed quite different techniques, datasets, and time periods. Perhaps as a consequence, the literature has also found mixed results on several dimensions. ${ }^{1}$ Most notably, the extent to which immigrants displace natives from STEM occupations remains hotly debated.

We provide in this paper a short glimpse into new data that are a useful platform for studying immigration within U.S. firms. The Longitudinal Employer-Household Dynamics (LEHD) database provides employeremployee records for U.S. private sector firms. We describe later a match of the LEHD to the Current Population Survey (CPS). The longitudinal nature of the person-level data affords new insights into career trajectories that to date has only been feasible in special settings (e.g., Borjas and Doran 2012a). The LEHD is also a powerful platform for studying firm-level consequences of immigration (e.g., Kerr et al. 2012).

This paper exploits the longitudinal power of the LEHD for the careers of individual

\footnotetext{
1 A brief sample of recent work includes Jennifer Hunt and Marjolaine Gauthier-Loiselle (2010), Kerr and William Lincoln (2010), Giovanni Peri and Chad Sparber (2011), George Borjas and Kirk Doran (2012a,b), Michael Clemens (2012), and Petra Moser, Alessandra Voena, and Fabian Waldinger (2012).
} 
workers. We ask a very simple question: Are job transitions for STEM workers particularly difficult when these workers are leaving their employer during periods of abnormally high immigration into the firm? The motivation for this question is straightforward. While native displacement can take several forms, critics of immigration often cite case studies where a native STEM worker feels that an immigrant has been hired by the former employer to replace him or her. Periods of abnormally high immigrant hiring by the firm are likely to be correlated with this latter phenomenon, to the extent that it exists, and we can examine the subsequent employment histories of departing workers for signs of displacement effects.

We find STEM career adjustments during periods of abnormally high immigration into the firm to be more difficult on several dimensions compared to non-STEM workers. Most notably, STEM workers do not acquire a new job as quickly as non-STEM workers; moreover, their earnings are reduced after the job transition occurs. This latter effect is strongest for the first five years, abating somewhat by the tenth year.

\section{LEHD Dataset}

The LEHD database is housed by the U.S. Census Bureau and requires confidential security clearance to access. The linked employer-employee records cover all privatesector firms in 29 states at present, including California, Florida, Illinois, and Texas. The records for most states start between 1990 and 1995; the records for all states currently end in 2008. Sourced from unemployment insurance wage records, the LEHD provides fairly limited information for workers beyond their quarterly earnings. Available traits of workers include their gender, age, place of birth, and citizenship status. These latter two variables afford analyses of immigration.

Unfortunately, the LEHD does not record occupations. A special match, however, has been made by the Census Bureau of LEHD records to respondents in the 1986-1997 Current Population Surveys (CPS). For this group, one can link in all of the information collected by the CPS during the survey year.

We center our sample selection on the 19951997 CPS surveys. We start with individuals surveyed by the CPS who are working in LEHD-covered states at the time of the survey. We retain workers who are observed to be departing from their employer at the time of the survey. As the CPS is a nationally representative sample, this group provides effectively a random sample over workers leaving their firms in LEHD-covered states.

We choose the three-year period of 19951997 to balance two goals. We first want to 
observe the subsequent career trajectory of these departing workers. With this design, we can track these workers for at least ten years. Second, LEHD records prior to 1995 provide additional empirical traction. We use these records to compare pre-period performances of workers and to formulate person-level controls on past labor market experiences.

Given our study's objectives, we further restrict the sample to workers with the following traits during the CPS sample year: natural-born U.S. citizens, aged 20-49, and earning \$2,500 or more (real 2008 dollars) in the quarter of departure from their main employer. The cut-off at 49 years old is designed to allow observation of a ten-year career trajectory without encountering issues related to retirements. The minimum earnings cut-off provides some sharper focus on workers with strong labor force participation.

Our analysis compares natives who are departing from their firm during times of abnormal immigrant hiring to those in time periods with lower immigrant hiring. This effect will be differentiated by whether or not the worker is in a STEM occupation at the time of the CPS interview, which is the same year as when they are departing their firm. It is essential to emphasize that we do not observe whether an employee's departure from a firm is voluntary or forced. We can thus only analyze whether there is systematic link to abnormally high immigration inflows that differs for STEM workers.

We measure abnormal immigration to the firm through the share of immigrants among a firm's new hires compared to the overall immigrant employment share of the firm. We select this measure due to its independence from firm growth. We want to avoid a metric like the number of immigrants hired compared to the firm's initial size, as this metric will be largely dictated by the firm growth rate (which could then be further linked to differences in who is departing and why). By looking at immigrant shares among new hires, we reduce the importance of firm growth. ${ }^{2}$

The on-line appendix compares worker traits by this dimension. While this technique falls short of achieving full randomization, it nonetheless performs reasonably well. When splitting the sample at the median value of abnormal immigration flows, differences between the two halves in terms of worker race, gender, and age distribution are quite small. Workers departing under abnormally high immigrant inflows, however, are more likely to have a college degree ( $31 \%$ vs. $24 \%$ ) and have higher earnings in the quarter of departure $(\$ 8,552$ vs. $\$ 7,118)$. They have also

\footnotetext{
2 We drop employees departing from firms that have no immigrants, as the ratio is undefined in these cases. This group is very small and their treatment does not impact our results.
} 
accumulated higher average quarterly wages $(\$ 7,994$ vs. $\$ 6,601)$ and one extra quarter of work over the past three years as evident in the employment histories of the LEHD. On the other hand, there are no material differences between the two halves of the sample with respect to past histories of switching employers or switching industries.

With respect to the firm ${ }^{3}$ from which the employees are departing, the group with abnormally high immigrant inflows has a somewhat higher representation in mining, construction, and manufacturing, but sector differences are not substantial. The firms are of very similar size. The employment growth rates are 0.08 and 0.10 for the high and low groups, respectively. These rates are measured relative to the average of start and end values. Finally, the overall immigrant employment shares of the two groups are comparable at $9.1 \%$ and $11.6 \%$, respectively.

Thus, while differences remain in the two halves of the sample, this technique does allow for reasonably comparable groups. As a safeguard, we further control in regressions for all of these observable traits. We have also confirmed that all results discussed below hold when excluding workers who do not have some college education as well. In terms of

\footnotetext{
${ }^{3}$ Firm traits are measured through State Employer Identification Numbers (SEIN). These traits will thus describe the local setting and employment conditions of large firms.
}

our focus on STEM workers, their representation in the two groups is likewise comparable: $5.3 \%$ and $4.1 \%$ of workers in the abnormally high and low immigration groups are STEM workers, respectively.

\section{Empirical Results}

We summarize our empirical results, and the on-line appendix provides the full table. Our least squares estimations take the form

$$
\begin{gathered}
\mathrm{Y}_{\mathrm{i}}=\varphi_{\mathrm{sjt}}+\beta \cdot \mathrm{X}_{\mathrm{i}}+\gamma \cdot \text { FirmImmigration }_{\mathrm{i}}+ \\
\delta \cdot \text { FirmImmigration }_{\mathrm{i}} \cdot \mathrm{STEM}_{\mathrm{i}}+\varepsilon_{\mathrm{i}}
\end{gathered}
$$

where $\mathrm{Y}_{\mathrm{i}}$ models various future employment outcomes for the departing worker. We include a vector of state-sector-year fixed effects $\varphi_{\text {sjt }}$ that broadly controls for many aspects of the local economy for workers. We also include a vector of person- and firm-level covariates $\mathrm{X}_{\mathrm{i}}$ that controls for measureable differences across departing workers in initial conditions. These covariates include all of the dimensions mentioned in the prior section when comparing worker traits. A central covariate is an indicator variable for whether the worker is employed in a STEM occupation when departing from his or her prior firm as observed through the CPS. This indicator is the main effect for our interaction (values reported in on-line appendix). 
The variable FirmImmigration ${ }_{i}$ models the degree to which abnormally high immigrant hiring is observed in the employee's firm at the time of the employee's departure. We discuss here results with a linear metric transformed to have unit standard deviation (SD). Results are similar when normalizing firm rates by local averages, and the appendix reports similar findings when splitting sample at the median value of relative inflows.

The $\gamma$ coefficient measures the effects of abnormally high immigration on worker transitions outside of STEM occupations. These coefficients, as reported below, are mostly small and statistically insignificant. Thus, in non-STEM occupations, this analysis does not find evidence that the difficulty of employment transitions is systematically correlated with the extent of immigration into the firm when the employee departs.

The interaction FirmImmigration ${ }_{i} \cdot \mathrm{STEM}_{\mathrm{i}}$ is the key focus of our work. This interaction measures the difference for STEM workers compared to the baseline, and the linear combination $\gamma+\delta$ provides the full impact for STEM workers. Regressions are unweighted, cluster standard errors by firm, and have 3,011 observations for most outcome variables.

We observe the following connections between employment transitions and abnormally high immigration rates:
- Observation in LEHD again: A basic but important starting point is whether there are differences in the rate at which we observe workers again in the LEHD. We may not observe workers again should they leave the workforce entirely, move outside of LEHD-covered states, or take up employment in the public sector. This analysis includes 3,327 workers. We find no effects on this dimension. A one SD increase in abnormal immigrant hiring is associated with a $-0.01(0.01)$ change in the likelihood of later observing a nonSTEM worker; the comparable effect for STEM workers is $0.00(0.03)$.

- Number of quarters with no employment evident in LEHD: We next consider the duration until workers are observed employed again in the LEHD. For most workers, this duration is zero quarters as the worker starts a new job immediately or has multiple jobs throughout (our focus is on departures from main jobs). Some workers, however, experience a long duration without an LEHD job. Using a maximum of 20 quarters, a one SD increase in abnormal immigrant hiring is associated with a $0.91(0.47)$ increase in the number of quarters before another LEHD job is observed for STEM workers. This compares to 0.05 (0.12) quarters for 
non-STEM workers. This duration without an LEHD job is likely evidence of one quarter of unemployment for STEM workers leaving their firm during periods of abnormally high immigration. ${ }^{4}$

- Number of quarters employed at next main job: We next consider how long the worker is at his or her next main job, again with a maximum of 20 quarters. This is tenure at the next job is the composite of multiple forces and thus does not have a single prediction. For example, displaced workers may need to take short-term jobs without long-term employment potential. On the other hand, displaced workers may seek very stable opportunities for future long-term employment. Perhaps reflecting this ambiguity, we find null effects on this margin, with increases of $0.54(0.58)$ and $0.21(0.16)$ quarters for STEM and nonSTEM workers, respectively, for each SD increase in abnormal immigration.

- Probability of switching industry for main job: Case studies often suggest that workers must switch industries or

\footnotetext{
4 The sample average is 2.8 quarters, with a majority of the sample experiencing zero quarters. Our data do not allow us to conclusively measure unemployment, and absence from the LEHD can be due to employment in the public sector, employment in states not covered by the LEHD, or self-employment without paid workers (e.g., Schedule C entrepreneurship). The first bullet point notes, however, that we do not observe any long-term differences in the likelihood of LEHD observation. Thus, these alternative reasons for not observing a worker in the LEHD would need to be short term before re-entering the sample. We do not see any particular reason why this would be true for STEM workers compared to non-STEM workers.
}

occupations as a result of the displacement. As we observe occupation once with the CPS, we can only measure industry switching. We do not observe a systematic link on this dimension. A one SD increase in abnormal immigrant hiring is associated with a $-0.02(0.11)$ increase in the likelihood of industry switching for a non-STEM worker; the comparable effect for STEM workers is $0.01(0.05)$.

- Log annualized earnings in the LEHD over the next year: We next consider earnings outcomes. Our first measure is the wage income of the worker in the following year. Wages are annualized using salaries from quarters worked, thus removing much of unemployment spells (partial quarters of unemployment remain). Wages sum over all jobs. On this dimension, we find more substantial bite. A one SD increase in abnormally high immigrant hiring at the time of a STEM worker's departure is associated with a $0.16(0.08)$ decline in log annualized wage earnings for the worker over the following year. There is only a $0.02(0.02)$ decline evident for non-STEM workers.

- Log annualized earnings in the LEHD over the next five and ten years: Our final step uses the extended employment histories of these workers to measure their 
wage outcomes over the next five and ten years. We only include in this analysis the 2,904 workers who we observe working in the LEHD in the fifth and tenth years after their focal departures. We continue to find substantial wage declines to the fifth year, with some abatement by the tenth year. A one SD increase in abnormally high immigrant hiring at the time of a STEM worker's departure is associated with a $0.18(0.07)$ decline in log earnings over the subsequent five years, and a 0.12 (0.08) decline over ten years. For non-STEM workers, wages over five and ten years are unchanged at $0.01(0.03)$ and $0.00(0.03)$.

Overall, these patterns suggest that STEM workers departing their firms during periods of abnormally high immigration into the firms experience difficult employment transitions. This framework is non-causal, and we hope future work is able to identify randomization in immigrant arrivals into firms to further quantify these effects (e.g., H-1B lotteries). More generally, employer-employee data offer great promise for better evaluating native displacement effects due to immigration.

\section{REFERENCES}

Borjas, George, and Kirk Doran. 2012a. "Intellectual Mobility: Native Responses to
Supply Shocks in the Space of Ideas", Working Paper.

Borjas, George, and Kirk Doran. 2012b. "The Collapse of the Soviet Union and the Productivity of American Mathematicians", Quarterly Journal of Economics 127:3, 1143-1203.

Clemens, Michael. 2012. "The Roots of Global Wage Gaps: Evidence from Randomized Processing of U.S. Visas", Working Paper.

Hunt, Jennifer, and Marjolaine GauthierLoiselle. 2010. "How Much Does Immigration Boost Innovation?", American Economic Journal: Macroeconomics 2, 3156.

Kerr, Sari Pekkala, William Kerr, and William Lincoln. 2012. "Skilled Immigration and the Employment Structures of U.S. Firms", Working Paper.

Kerr, William, and William Lincoln. 2010. "The Supply Side of Innovation: H-1B Visa Reforms and U.S. Ethnic Invention", Journal of Labor Economics 28:3, 473-508.

Moser, Petra, Alessandra Voena, and Fabian Waldinger. 2012. “German Jewish Emigres and U.S. Invention", Working Paper.

Peri, Giovanni, and Chad Sparber. 2011. "Highly-Educated Immigrants and Native Occupational Choice", Industrial Relations $50: 3,385-411$. 


\section{Appendix to}

"Immigration and Employer Transitions for STEM Workers"

\section{Authors and Contact Information:}

Sari Pekkala Kerr: Wellesley College, 106 Central Street, Wellesley, MA 02481 (e-mail:

skerr3@wellesley.edu).

William R. Kerr (corresponding): Harvard University, NBER, and Bank of Finland, Rock Center 212, Harvard Business School, Boston, MA 02163 (wkerr@hbs.edu).

\section{Data Access:}

Research requires confidential access to the LEHD dataset through the U.S. Census Bureau. Programs and data for this research are archived in folder br0786/data/immig/programs/earnings/aea. 
Table 1: Traits of departing native workers by employer-level immigration

Sample split by abnormal immigrant hiring in year of employee departure compared to firm's baseline employment

\begin{tabular}{|c|c|c|c|}
\hline High & Low & Difference & Ratio \\
\hline \multicolumn{4}{|c|}{ in year of CPS observation during 1995-1997 } \\
\hline $0.869(0.009)$ & $0.875(0.008)$ & $-0.006(0.012)$ & -0.007 \\
\hline $0.541(0.013)$ & $0.528(0.012)$ & $0.013(0.018)$ & 0.024 \\
\hline $0.392(0.013)$ & $0.400(0.012)$ & $-0.008(0.017)$ & -0.020 \\
\hline $0.355(0.012)$ & $0.341(0.011)$ & $0.014(0.017)$ & 0.040 \\
\hline $0.253(0.011)$ & $0.259(0.010)$ & $-0.006(0.015)$ & -0.023 \\
\hline $0.074(0.007)$ & $0.104(0.007)$ & $-0.030(0.010)$ & -0.337 \\
\hline $0.283(0.012)$ & $0.309(0.011)$ & $-0.026(0.016)$ & -0.088 \\
\hline $0.333(0.012)$ & $0.351(0.011)$ & $-0.018(0.017)$ & -0.053 \\
\hline $0.311(0.012)$ & $0.236(0.010)$ & $0.075(0.016)$ & 0.274 \\
\hline $0.053(0.006)$ & $0.041(0.005)$ & $0.012(0.007)$ & 0.255 \\
\hline $8,552(129)$ & $7,718(113)$ & $834(172)$ & 0.103 \\
\hline \multicolumn{4}{|c|}{ d in LEHD over years prior to CPS observation } \\
\hline $7,944(141)$ & $6,601(127)$ & $1,342(189)$ & 0.185 \\
\hline $8.850(0.092)$ & $7.989(0.091)$ & $0.861(0.129)$ & 0.102 \\
\hline $3.761(0.043)$ & $3.553(0.042)$ & $0.208(0.060)$ & 0.057 \\
\hline $0.434(0.013)$ & $0.462(0.012)$ & $-0.028(0.017)$ & -0.063 \\
\hline \multicolumn{4}{|c|}{ bsservation during 1995-1997 } \\
\hline $0.275(0.012)$ & $0.231(0.010)$ & $0.044(0.015)$ & 0.174 \\
\hline $0.239(0.011)$ & $0.302(0.011)$ & $-0.063(0.016)$ & -0.233 \\
\hline $0.485(0.013)$ & $0.467(0.012)$ & $0.018(0.018)$ & 0.038 \\
\hline $6.183(0.050)$ & $5.939(0.046)$ & $0.244(0.068)$ & 0.040 \\
\hline $0.081(0.008)$ & $0.102(0.011)$ & $-0.021(0.014)$ & -0.230 \\
\hline $0.091(0.002)$ & $0.116(0.002)$ & $-0.025(0.003)$ & -0.242 \\
\hline
\end{tabular}

Notes: Estimations consider employment transitions of a random sample of workers who were surveyed by the CPS during 1995-1997 and were present in an LEHD-covered state. The sample is restricted to workers with the following traits during the CPS sample year: natives aged 20-49, earning $\$ 2,500$ or more in the quarter of departure (real 2008 dollars), and departing their main employer. 
Table 2a: Regression comparison of employment transition rates and conditions

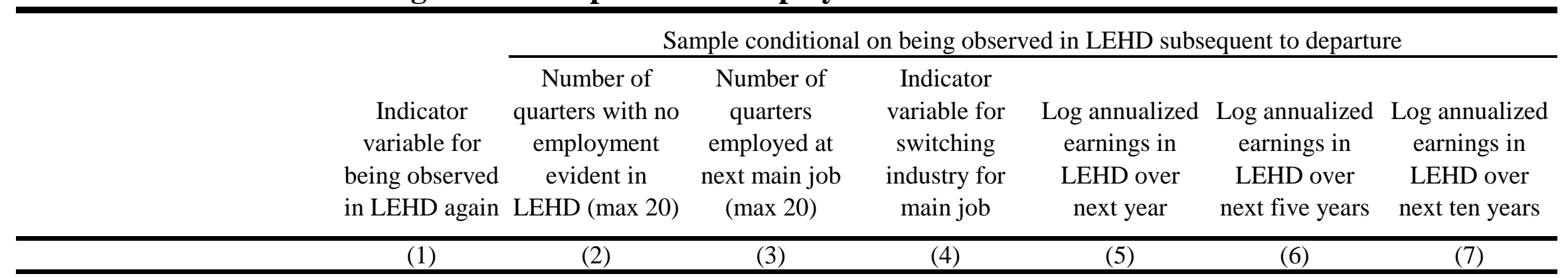

Estimations with linear immigration factor transformed to have unit standard deviation

\begin{tabular}{lccccccc} 
Ratio of abnormal immigrant & -0.007 & 0.050 & 0.205 & -0.016 & -0.020 & 0.011 & 0.004 \\
hiring at time of departure & $(0.007)$ & $(0.120)$ & $(0.158)$ & $(0.011)$ & $(0.023)$ & $(0.026)$ & $(0.027)$ \\
x $(0,1)$ indicator variable for & 0.004 & 0.863 & 0.338 & 0.028 & -0.138 & -0.191 & -0.120 \\
STEM worker & $(0.033)$ & $(0.476)$ & $(0.595)$ & $(0.050)$ & $(0.079)$ & $(0.070)$ & $(0.079)$ \\
$\begin{array}{l}(0,1) \text { indicator variable for } \\
\text { STEM worker }\end{array}$ & -0.028 & 0.401 & -0.500 & 0.019 & 0.146 & 0.161 & 0.106 \\
Observations & $(0.029)$ & $(0.483)$ & $(0.597)$ & $(0.046)$ & $(0.079)$ & $(0.082)$ & $(0.092)$ \\
Linear combination of first & 3,327 & 3,011 & 3,011 & 3,011 & 3,011 & 2,904 & 2,904 \\
two rows for STEM worker & -0.003 & 0.913 & 0.544 & 0.012 & -0.158 & -0.180 & -0.116 \\
\hline
\end{tabular}

Notes: See Table 1. OLS estimations consider employment transitions of a random sample of workers who were surveyed by the CPS during $1995-1997$ and were present in an LEHD-covered state. Column headers indicate subsequent employment outcome variables measured through the LEHD. The main regressors are the degree to which abnormally high immigrant hiring is observed in the employee's firm at the time of the employee's departure and an interaction of this hiring trait with whether or not the employee is working in a STEM occupation. Abnormal immigrant hiring is measured through the ratio of immigrants among hires compared to the overall immigrant employment share of the firm. This variable is entered linearly and transformed to have unit standard deviation in Table $2 \mathrm{a}$. In Table $2 \mathrm{~b}$, the sample is split at the median value of the ratio with an indicator variable. Similar results are found if normalizing the immigrant inflows by the average rate in their state-sector-year. Regressions include state-sector-year fixed effects, include employee and firm covariates identified in the text and shown in Table 1, are unweighted, and cluster standard errors by firm. Sectors are defined at the one-digit SIC level. 
Table 2b: Regression comparison of employment transition rates and conditions

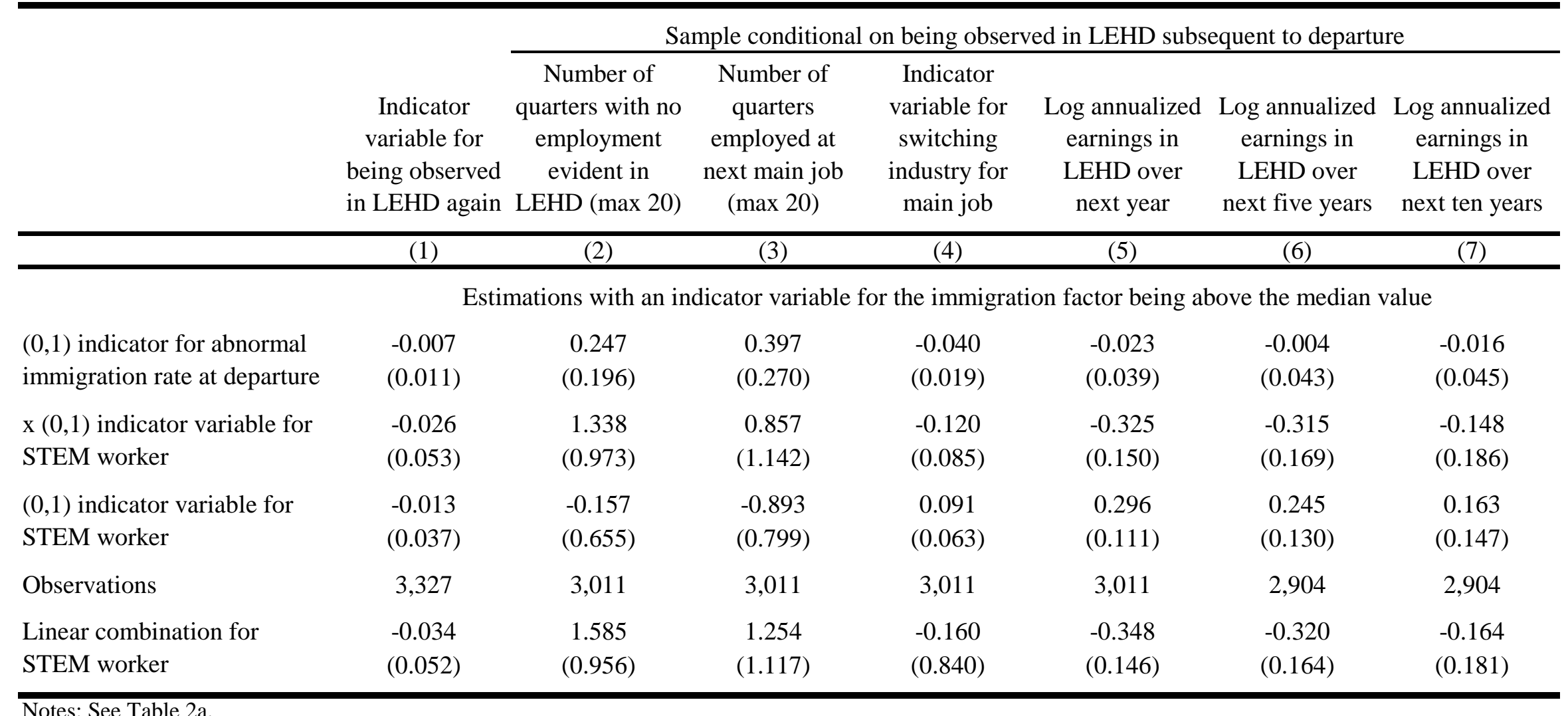

Notes: See Table 2a. 